\title{
La apropiación husserliana del Imperativo Categórico
}

\author{
Celia Cabrera \\ Universidad de Buenos Aires/CONICET/CEF-ANCBA
}

"Cada hombre se encuentra-habrá que decir con la fórmula kantiana-bajo un imperativo categórico. Solo puede ser un 'hombre verdadero', valorable como bueno sin más, en la medida en que voluntariamente se somete a sí mismo al imperativo categórico; a este imperativo que, por su parte, no dice otra cosa que: 'Sé hombre verdadero. Conduce tu vida de modo que siempre puedas justificarla en la evidencia.Vive en la razón práctica"”."

\begin{abstract}
Resumen: Los intentos de Husserl por elaborar una ética formal análoga a la lógica culminan con la formulación de una ley formal superior de la práctica, i.e., el imperativo categórico, considerado por él como el problema central de la ética. Tal formulación se presenta como el núcleo de un sistema ético que pretende, en su nivel más fundamental, determinar las leyes formales de la acción correcta. En este marco, el objetivo del artículo es intentar determinar el significado preciso, la función y el alcance de la apropiación husserliana del imperativo categórico, y su relación con el sistema que constituye su referente fundamental en la elaboración de una ética formal: la ética kantiana.
\end{abstract}

Palabras clave: fenomenología; Husserl; Kant; ética; imperativo categórico

\begin{abstract}
Husserl's Appropriation of the Categorical Imperative". Husserl's attempts to elaborate a formal ethics analogous to logic reaches its highest point in the formulation of a superior formal law of practice, i.e., the categorical imperative, considered by him to be the central problem in ethics. Such formulation constitutes the main core of a system that, at its most fundamental level, aims to determine the formal laws of correct action. In this framework, the aim of the paper is to determine the precise meaning, function and scope of the Husserlian appropriation of the categorical imperative and its relationship with its main reference in the elaboration of a formal ethics: Kantian ethics.
\end{abstract}

Keywords: phenomenology; Husserl; Kant; ethics; categorical imperative

*Husserl, E., Renovación del hombre y la cultura. Cinco ensayos, 1ra. edición, Serrano, A. (trad.), Barcelona: Anthropos Editorial, 2002, p. 38. 


\section{Introducción}

Inscribiéndose en la tradición kantiana y, en especial, bajo la influencia de Franz Brentano, Husserl reconoce la formulación del imperativo categórico como "el problema central de la ética"1. Tal formulación representa, para él, el núcleo de todo sistema ético que pretenda, en su nivel más fundamental, determinar las leyes formales de la acción correcta y dar cuenta, de este modo, de una obligación objetivamente vinculante. En este marco, el objetivo del presente artículo es intentar esclarecer el significado preciso, la función y el alcance de la apropiación husserliana del imperativo categórico. Como sabemos, el imperativo categórico expresa un deber (Sollen) que, a diferencia de las exigencias hipotéticas, se presenta a los sujetos con un carácter incondicionado, esto es, no limitado a una condición determinada, sino válido bajo todo supuesto. Como toda ley esencial, el imperativo categórico expresa una necesidad que es independiente de nuestra vida fáctica pero adquiere significado en su conexión con ella, actuando como guía para nuestra conducta. Las leyes de la axiología y la práctica formal, formuladas por Husserl en sus cursos tempranos, establecen que toda decisión requiere una toma de posición respecto de un grupo de posibilidades, un acto en el que otorgamos prioridad al valor de una de ellas frente a otras. Así, la posibilidad de formular un imperativo categórico dependerá de la delimitación de un campo práctico con un número determinado de elecciones posibles. En virtud de esto, uno de los ejes centrales de la tematización temprana del imperativo será la posibilidad de convertir la exigencia relativa a la que da lugar la llamada "ley de aborción" (Absorptionsgesetz) en una exigencia objetiva. En este contexto, el análisis de Husserl nos enfrenta a un importante tema: la exigencia de imparcialidad práctica sugerida por la apelación a un "espectador desinteresado" (unbeteiligte Zuschauer) y la idea de un summum bonum formaliter spectatum. A partir de allí, nos dedicamos a mostrar cómo, en los cursos tempranos, las consideraciones objetivas acerca de la corrección de la voluntad revelan su insuficiencia y plantean la necesidad de una reelaboración

\footnotetext{
1 Hua XXVIII, p. 137. La sigla Hua, con indicación de tomo en numerales romanos y página, en arábigos corresponde a Husserl, E., Gesammelte Werke-Husserliana, 40 vv., Biemel, W. y otros (eds.), Dordrecht: Springer (anteriormente, Kluwer Academic Publishers y Martinus Nijhoff), 1950-2009. Las traducciones son propias, a menos que se indique lo contrario.
} 
noética de la exigencia categórica, es decir, una consideración de la evidencia de la racionalidad de una meta volitiva, que hace de una voluntad meramente correcta (richtig) "la mejor voluntad" (der beste Wille). Nuestra presentación de la apropiación husserliana del imperativo categórico, centrada hasta dicho punto en la exposición de lecciones tempranas sobre ética, aborda, ulteriormente, la reelaboración de la concepción del deber práctico que tiene lugar en textos posteriores, en los que el ideal ético no es solo el de hacer lo mejor en cada situación, sino llegar a ser cada vez mejor y vivir "la mejor vida posible". En este contexto, debemos tener en cuenta que los escritos de Husserl sobre ética pueden dividirse en dos grandes grupos: aquellos que provienen de los cursos dictados en Halle y Gotinga entre 1891 y 1914², y el material de los cursos, artículos y manuscritos de investigación posteriores a 1917/18, especialmente los elaborados en la década de 1920 y comienzos de los años 30. Los textos del primer grupo corresponden a lo que hemos denominado "ética temprana" y los del segundo grupo a una "ética posterior" o "tardia"3. En los primeros cursos, el tema que se halla en primera linea entre las preocupaciones de Husserl es la mencionada elaboración de una ética formal capaz de superar las amena-

2 El material de estos cursos se encuentra publicado en Hua XXVIII. El texto principal del volumen está compuesto por los tres cursos del semestre de invierno de 1908/09 (Grundprobleme der Ethik), del semestre de verano de 1911 (Grundprobleme der Ethik und Wertlehre) y del semestre de verano de 1914 (Grundfragen der Ethik und Wertlehre). De los cinco cursos dictados en sus años de Privatdozent en Halle (entre 1891 y 1897) se conservan muy pocos textos. En rigor, se conservan solo tres fragmentos de los comienzos de algunas de las lecciones. Uno de ellos es una muy breve introducción a la lección Ethik und Rechtsphilosophie del semestre de verano de 1897, donde Husserl ya plantea como objetivo la refutación del escepticismo ético y la fundamentación científica de la ética. Esta sección introductoria es recogida como texto complementario $\mathrm{N}^{\circ} 1$ en Hua XXVIII. Este tomo incluye, asimismo, como textos complementarios $\mathrm{N}^{\circ} 2$ y $\mathrm{N}^{\circ} 3$, una extensa sección del primer curso sobre ética impartido en la Universidad de Gotinga, el curso de 1902, Grundfragen der Ethik, cuyo tema central es el análisis de la filosofia de Hume, como representante de las morales sentimentalistas, y de Kant, como representante de las morales intelectualistas.

3 Ullrich Melle se refiere a la distinción entre una "ética de pre-guerra" y una "ética de postguerra", poniendo de relieve las consecuencias de la tragedia de la Primera Guerra Mundial en el pensamiento ético de Husserl. Cf. Melle, U., “The Development of Husserl's Ethics”, en: Études Phénoménologiques, v. VII, 13-14 (1991), pp. 115-135. Cabe señalar que las reflexiones de la "ética de post-guerra" no presentan tampoco ellas mismas un carácter unitario. Los textos posteriores a 1918 pueden dividirse entre aquellos que ponen especial énfasis en la configuración racional de la vida, la autodeterminación, la autorregulación, la constante autocrítica y la auto-preservación y aquellos que acentúan el tema del amor, los valores absolutos y el deber absoluto. Los primeros corresponden fundamentalmente a los artículos preparados en 1922/23 para la revista japonesa The Kaizo (publicados en Hua XXVII), en los que la idea de la autorregulación de la vida es abordada en términos de una exigencia de "renovación" (Erneuerung) del hombre individual y de la colectividad humana. Los segundos se encuentran mayormente en manuscritos de investigación (algunos de ellos han sido publicados en la sección IV de Hua XLII, titulada "Reflexionen zur Ethik aus den freiburger Jahren"). 
zas del escepticismo y del relativismo ético. Por otro lado, los textos de la ética tardia ponen en el centro de la discusión la dimensión situacional de la toma de decisión y se basan en una profundización de la noción de "persona ética" y en un concepto teleológico y abarcador de la vida ética como un proceso de autorregulación en función de una meta. En este marco, sin pretender realizar una exposición exhaustiva del tema, nuestro objetivo será señalar algunas de las consecuencias que tuvieron los cambios operados en la concepción husserliana del sujeto ético y de la vida ética en la determinación del imperativo categórico. Finalmente, la última sección del artículo estará destinada a la elucidación del carácter específico de la apropiación fenomenológica del imperativo categórico mediante el análisis de las críticas realizadas por Husserl a quien fuera su referente ineludible en la elaboración de una ética formal: Immanuel Kant.

\section{La determinación formal del imperativo en los cursos tempranos}

La "ley de absorción" formulada en el marco de la práctica formal conduce a la idea de un bien superior o "más alto" (höchstes Gut). La determinación de la corrección de la voluntad depende de un proceso de ponderación de alternativas tendiente a establecer cuál de ellas posee el mayor valor en una situación concreta. De acuerdo con Husserl, la "ley de absorción" nos permite determinar qué opción tiene un valor superior: solo aquella que absorbe el valor de toda otra, sin ser ella misma absorbida, posee valor práctico absoluto. Lo "debido" (Gesolltes), luego, es lo mejor dentro de una disyunción de opciones. Correlativamente, es incorrecto querer algo que, en un campo de posibilidades dado, posea menor valor; una voluntad correcta (richtig) es una voluntad que quiere la realización del bien más alto. Tomando como eje esta ley, en sus lecciones tempranas sobre ética y axiología, Husserl enuncia la determinación formal del imperativo categórico con la siguiente formula: “¡Haz lo mejor entre lo alcanzable en toda tu esfera de influencia práctica!"4. Esta formulación coincide con el imperativo categórico de Brentano, quien en sus lecciones sobre ética, junto a la formula

\footnotetext{
4 "Tue das Beste unter dem erreichbaren Guten innerhalb deiner jeweiligen praktischen Gesamtsphäre!" (Hua XXVIII, p. 142). El imperativo categórico hace su primera aparición en el curso Problemas fundamentales de ética, dictado en 1908/1909 en la Universidad de Gotinga, y se reitera en los cursos de 1911 y 1914. El Apéndice IX de Hua XXVIII recoge la formulación del curso de 1908/09 incluyendo una leve modificación respecto de la arriba citada: “¡Haz en todo momento lo mejor entre lo alcanzable en toda tu esfera de influencia racional?" ("Tue jederzeit das Beste unter dem Erreichbaren in der gesamten, deiner vernünftigen Einwirkung unterworfenen Sphäre!") (Hua XXVIII, p. 350, énfasis propio). Esta formulación agrega la referencia temporal (jederzeit) y la mención a la racionalidad.
} 
"elige lo mejor entre lo alcanzable" (Wähle das Beste unter dem Erreichbaren), incluye también una formulación negativa que prescribe: "nunca te decidas en tu elección por un valor menor entre lo alcanzable"s. A la formulación noética de Brentano -según Husserl, "ciertamente sobrecargada" pero que "no debe mejorarse en nada esencial" "- se agrega el principio noemático según el cual "lo mejor entre lo alcanzable en todo el ámbito práctico no solo es comparativamente lo mejor sino lo único prácticamente bueno"? Una formulación posterior del curso de 1914 retoma una expresión popular asimismo recogida por Brentano y enuncia que "en el círculo de lo prácticamente alcanzable, lo mejor es enemigo de lo bueno; descartar lo mejor es incondicionalmente incorrecto, elegir lo mejor posible es exigido incondicionalmente como lo único y, por eso, absolutamente correcto"8.

En toda situación volitiva hay algo que es exigido, excepto en aquellas en las que todas las posibilidades prácticas concernidas sean igualmente indiferentes (adiáforas). En este caso, no se puede decir que se actúe correctamente o incorrectamente al elegir la realización de una opción entre otras, ya que no hay alli ningún deber, nada es exigido. "Quien elige algo indiferente -bajo el supuesto de que no hay ningún bien positivo en cuestión- no entra en conflicto con ningún deber, no actúa de modo inconveniente, no actúa de modo incorrecto, pero tampoco de manera correcta, conveniente, en el sentido de la voluntad. No hace nada que sea debido, pero no hay alli tampoco ningún deber. No ejercita la razón volitiva, esta última solo concierne a la conveniencia" 9 . A esto, Husserl agrega que en el caso de que el que el dominio práctico esté compuesto solamente por valores negativos, lo que es correcto es la omisión. "Toda decisión o querer dirigido a un no-valor es, considerado en sí mismo, incorrecto. De modo que una elección, una pregunta volitiva, que se dirige exclusivamente a no-valores, da como resultado que toda decisión de elección

\footnotetext{
5 "Entscheide dich in deiner Wahl niemals für etwas minder Gutes unter dem Erreichbaren" (Brentano, F., Grundelung und Aufbau der Ethik, 1ra. edición, Bern: Francke Verlag, 1952, p. 307. (En adelante: GAE)). Cf. Vom Ursprung sittlicher Erkenntnis, 2da. edición, Leipzig: Meiner, 1922, p. 16 (En adelante: USE).

Hua XXVIII, p. 351.

Ibid.

8 "Im Kreis des praktisch Erreichbaren ist das Bessere der Feind des Guten; das Bessere hintanzusetzen ist unbedingt unrichtig, das Bestmögliche <zu> wählen, ist unbedingt gefordert als das einzige und darum absolut Richtige" (Ibid., p. 140).

9 Ibid., p. 135.
} 
que culmina aquí positivamente es incorrecta. Esto significa que: es correcto omitirlos, sin plantear la pregunta sobre qué es más o menos malo" ${ }^{10}$.

Por otro lado, no se puede exigir a priori de un sujeto aquello que él no puede alcanzar: lo que debo está determinado por lo que puedo, de modo que "lo que alguien no puede hacer, no debe tampoco hacerlo"11. Para ilustrar esta limitación práctica, Husserl se refiere al plan de ser un jefe de ejército, un gran reformador o el fundador de una religión, y sostiene que se trata de metas que dependen de tantas circunstancias azarosas que debo aceptar que seria altamente improbable alcanzarlas, incluso si considero que poseo los dones que se requieren para ello: "tengo un horizonte vacío pleno de posibilidades vacías... a ese horizonte puedo tratarlo como no existente. Tengo que limitarme a los bienes alcanzables con certeza o con una cierta probabilidad finita"12. El criterio de posibilidad de realización práctica restringe aquello que puede ser exigido, así como también lo que puede ser objeto de la voluntad en general. En este sentido, en los estudios sobre fenomenología de la voluntad, Husserl sostiene que la voluntad, a diferencia del mero desear, implica la conciencia de la posibilidad de realización práctica de lo querido. El deseo y la voluntad se presentan a menudo entrelazados, pero el simple desear no es un querer y no es correcto decir que quiero aquello que sé que no puedo cumplir. La voluntad tiene un límite en cuanto no puede dirigirse a algo ideal ni tampoco a algo pasado; un acto volitivo se refiere siempre a algo futuro prácticamente posible ${ }^{13}$. La consideración de lo prácticamente posible otorga un rol a la subjetividad que no tiene análogo en la esfera de la verdad y el juicio. Una verdad objetiva lo es en sí misma, no lo es para tal o cual sujeto. En contraste, lo que es para mí una posibilidad práctica, puede no serlo para otro sujeto. Las posibilidades prácticas se hallan referidas al sujeto volitivo del caso, nunca son idénticas para dos sujetos ni tampoco lo son para un mismo sujeto, en virtud de que se modifican en cada punto temporal (Zeitpunkt). Cada sujeto y el mismo sujeto en distintos puntos temporales pueden y, por consiguiente, "deben" (sollen) algo distinto ${ }^{14}$.

10 Ibid., p. 134.

11 "Was jemand nicht kann, das soll er auch nicht" (Ibid., p. 149).

12 Ibid., p. 158.

13 Cf. ibid., p. 103ss.

14 "Einen Willen für sich herausnehmen und nach seiner Wahrheit fragen, das ergibt nie eine Wahrheit für sich und an sich gültig. Jede Willenswahrheit ist nur Wahrheit im universalen Willenszusammenhang des betreffendes Willenssubjekts, nur im Bezug auf das volle individuelle Leben kann von der Wahrheit irgendeines Willens, also von dem, was das Subjekt darin wahrhaft 
A excepción de los casos mencionados, la formulación del imperativo expresa la convicción de que en toda elección con un número finito de opciones hay una mejor opción y que lo téticamente ${ }^{15}$ exigido es dirigir la voluntad hacia ella y hacia ninguna otra. Naturalmente, un imperativo categórico requiere que la determinación de "lo mejor" no deje ningún lugar a equivocidades, lo absolutamente debido no puede ser, por su sentido mismo, "lo relativamente mejor". Sin embargo, la determinación del deber mediante la ley de absorción todavía conserva un resto de relativización pues, ¿cómo es posible establecer de una vez por todas que un valor y, por ende, el deber al que da lugar, no puede ser absorbido por otro? Husserl reconoce que la sola noción de absorción no da lugar a un deber absoluto, sino a un deber relativo, es decir, que no llegamos aún a un imperativo categórico, sino a uno "bajo reserva" (unter Vorbehalt) ${ }^{16}$. El paso de un deber bajo reserva a uno categórico supone aún algunas precisiones.

\section{El campo práctico y el espectador desinteresado}

Husserl se refiere a la situación arriba anunciada del siguiente modo: “¿Qué define a un imperativo categórico? Precisamente, la imposibilidad de ser absorbido. ¿Pero sabemos por adelantado que hay en cada caso dado para el sujeto volitivo un deber no absorbible, algo mejor que no puede ser superado? Lo único que sabemos es que en toda elección que tiene lugar en un campo práctico delimitado consistente en un número finito de opciones hay una mejor, en caso de que haya en el campo práctico algún bien en absoluto. Lo mejor puede ser ocasionalmente ambiguo, podemos conformarnos con eso. Es un axioma que dada una pluralidad de optima iguales, es erróneo no elegir uno de ellos o que elegir uno de ellos, no importa cuál, es correcto o prácticamente requerido aunque solo sea de manera relativa./ / Manifiestamente, la relatividad, la validez bajo reserva de una elección cualquiera reside en que le falta una delimitación de validez última. Pues es casual hacia dónde dirige su interés volitivo la persona que elige y hasta dónde abarca la disyunción en cuestión. Él puede incorporar nuevas posibilidades prácticas y en cada ampliación del dominio práctico, hablando de modo general, el optimum se modificará. Con esta ampliación, los miembros absorbidos en los niveles previos podrían incluso adquirir una nueva

soll, gesprochen werden. Was ich soll, ist bestimmt durch das ,ich kann' und was ich kann ist ein anderes, als was ein jeder andere kann" (Hua XXXVII, p. 252).

${ }^{15}$ Husserl utiliza los términos "categórico" y "tético" como sinónimos. Cf. Hua XXVIII, p. 214.

16 Ibid., p. 136. 
significación. Lo que es mejor en una elección, en los límites de su dominio práctico, es lo exigido prácticamente, pero solo bajo la restricción de que esta ampliación no de como resultado algo mejor que lo absorba" ${ }^{17}$.

A la luz de esto, el tránsito desde la exigencia hipotética, resultante de la ley de absorción, a la exigencia categórica incondicionada requiere considerar el campo de acción práctico como si estuviera objetivamente cerrado: "Es claro que la posibilidad de un imperativo categórico depende de la posibilidad de descubrir un dominio práctico determinado que le pertenezca objetivamente, un campo de acción (Wirkungsfeld) práctico que le pertenezca objetivamente, que sea objetivamente cerrado y que no sea susceptible de ampliación, y esto por cada momento (Zeitpunkt) en el que el yo se pueda plantear una pregunta volitiva en general. ¿Hay posiblemente algo tal para un yo singular?, ¿o lo hay a priori para todo yo?"18 Como adelantamos en el apartado anterior, el ámbito de posibilidades en cuestión es determinado por la referencia al sujeto volitivo y a cada momento temporal en que él se plantea la toma de decisión. Como no puede ser descartado a priori que la modificación del ámbito práctico (mediante la adición de opciones elegibles) modifique el valor de cada una de las posibilidades singulares, solo cuando el ámbito de posibilidades está cerrado y el punto temporal determinado, la ley de absorción da lugar a un deber objetivo. El resultado debe ser la exposición de una disyunción completa de bienes alcanzables; en esta disyunción, además, cada miembro debe estar constituido de tal manera que no pueda ser ampliado por ningún aumento de bienes u otros objetos valiosos sin perder valor práctico. En relación con tal disyunción ideal, se dice, entonces, que "lo mejor entre estos posibles bienes prácticos es lo únicamente exigido, es lo mejor entre lo alcanzable, es lo absolutamente debido" 19 . Luego, que dos sujetos elijan de maneras distintas o que el mismo sujeto en distintos puntos temporales elija de manera distinta tiene como único fundamento legítimo el hecho de que su situación fáctica es en cada caso diferente: "las mismas leyes de esencias, materiales y formales, exigen, naturalmente según el caso de aplicación, decisiones diferentes, pero en cada caso exigen una decisión determinada"20.

En este punto Husserl apela a una idealización, que concierne tanto al campo de acción como al sujeto volitivo. El imperativo formal no puede

\footnotetext{
${ }_{17}^{17}$ Ibid., p. 136. La doble barra (//) indica la existencia de un punto aparte en el original.

${ }^{18}$ Ibid., pp. 136-137.

${ }_{19}$ Ibid., p. 351.

${ }^{20}$ Ibid., p. 139.
} 
prescribir actuar de una manera específica a menos que se estipule un rango limitado de posibles elecciones que por definicion, es decir, idealiter, no sean susceptibles de ampliación. Por su parte, el sujeto debe situarse a sí mismo en una posición de neutralidad o imparcialidad desde la cual observa y juzga su elección desde el punto de vista de su corrección. Así, el ámbito de posibilidades prácticas para un sujeto concreto, en cuanto campo de acción idealmente cerrado, debe ser accesible al razonamiento de todos los sujetos, de modo que "si un sujeto actúa correctamente, todo otro sujeto debería actuar del mismo modo, si su campo práctico es transformado en el de la persona que actúa, y esto se justifica precisamente en el hecho de que lo que prescribe la corrección son leyes de esencia que solo encuentran aplicación en el caso singular dado fácticamente y en el sujeto fáctico"21. Siguiendo las leyes de la razón axiológicopráctica, todo sujeto debería ser capaz de "calcular" cuál sería la demanda ética objetiva en una situación específica. "El observador desinteresado (unbeteiligte $Z$ uschauer) es un sujeto que valora racionalmente, que se convence de que las convicciones que fundan su acción son correctas, que las evaluaciones del bien son efectuadas con corrección, que lo que valoramos como bueno debería, en efecto, según su esencia, y así generalmente, y según las leyes aprióricamente materiales del valor, ser valorado como bueno; y que, en la esencia de los valores de bien, son exactamente tales preferencias y ningunas otras las que tienen un sostén legítimo, que, por ese motivo, lo mejor es efectivamente lo mejor"22.

El punto de vista teórico de la axiología y la práctica formal, y la noción de un espectador imparcial u observador desinteresado aluden a un "control neutral de la corrección" 23 de la decisión realizable por cualquier sujeto. Esta posición de neutralidad deja fuera de consideración la orientación del agente hacia metas personales; la acción correcta es precisamente la que trasciende esos condicionantes en dirección hacia un punto de vista externo. En resumen, la ficción de un "observador o espectador imparcial" deja en evidencia la acti-

\footnotetext{
${ }^{21}$ Ibid., p. 139. Otro fragmento del mismo texto amplia la idea a la que nos referimos del siguiente modo: "Incluso si el dominio de la voluntad práctica de cada sujeto es distinto del de otros sujetos -si, por hablar en general, no son bienes de la misma especie los que entran en cada uno de los dominios de este tipo, y si, por consecuencia, lo que es mejor prácticamente es diferente para cada uno de los sujetos-, todo sujeto racional debe por lo menos reconocer que alli donde alguien evalúa con corrección algo como bueno de tal o tal forma, todo aquel que toma en consideración la misma materia debería evaluar del mismo modo; y de la misma manera, todo sujeto racional debería evaluar que, si un dominio contiene tales o tales bienes como posibilidades prácticas, para tal dominio lo mejor se halla pre-delineado idealiter" (Ibid., p. 138).

22 Ibid., pp. 138-139.

${ }^{23}$ Trincia, F. S., "The Ethical Imperative in Edmund Husserl”, en: Husserl Studies, v. XXIII, 3 (2007), pp. 169-186, p. 172.
} 
tud metodológica de "desapego" que demanda la acción ética. Ahora bien, ¿es posible ser imparcial no solo respecto de los demás sujetos sino, especialmente, respecto de mí mismo y de mis propias metas? Es preciso enfatizar aquí que la exigencia de imparcialidad que expresa la alusión a un espectador desinteresado es parte del nivel formal de reflexión ética que, en adelante, comenzará a revelarse como incompleto. En el siguiente apartado comenzaremos a precisar esta determinación del deber práctico mediante el señalamiento de un aspecto de la decisión ética que hasta aquí no ha sido tomado en consideración: que la acción ética no concierne simplemente a la elección de lo mejor, sino a la elección de lo mejor por los motivos correctos.

\section{El querer evidente}

Las consideraciones objetivas hasta aquí presentadas no son completamente satisfactorias para Husserl, pues no se puede decir aún que "hemos llegado al final" 24 . La determinación formal del imperativo, que prescribe hacer lo mejor en el ámbito de las posibilidades prácticas, establece una norma para la corrección objetiva de la voluntad. No obstante, esta norma requiere una complementación, ya que queda todavía un sentido del concepto de "deber" que no ha sido tomado en consideración. El aspecto aún no abordado concierne a las motivaciones de la elección, pues una voluntad correcta en términos objetivos puede no ser "la mejor voluntad" (der beste Wille), si lo que está en su base no es un acto racionalmente motivado. La analogía con la esfera del juicio es nuevamente útil para ilustrar este punto. Un juicio puede dirigirse a la verdad y, si es confirmado mediante la constatación de un estado de cosas verdadero, decimos que él es correcto (richtig). Sin embargo, la persona que juzga puede juzgar correctamente de manera casual (zufällig) o bien guiada por una determinación pasiva que carece de motivación en la intuición evidente. Lo que está en juego aquí es la distinción entre un juicio meramente correcto y un juicio racional. Juzgar racionalmente no es simplemente juzgar correctamente; un juzgar correcto puede serlo por obra del azar y no porque quien juzga está convencido de su pertinencia (Triftigkeit). Lo mismo sucede en la esfera de la voluntad. La voluntad puede ser ciega o puede ser evidencial (einsichtig), o (lo que es lo mismo) racional (vernünftig). La mejor voluntad no puede ser ni ciegamente ni casualmente correcta, "la voluntad es la mejor

${ }^{24}$ Hua XXVIII, p. 152. 
voluntad cuando es evidencial"25. De este modo, lo exigido incondicionalmente no es solamente querer lo mejor, sino una voluntad que se dirige hacia lo mejor de manera racional en la intuición evidente. Esto significa que "no solo debo preguntarme qué puedo, y sopesar qué es lo mejor, y adoptar en mí mismo una actitud racional, sino que debo deliberadamente aspirar a la meta de la mayor claridad y racionalidad posibles, por medio de lo cual no solo aseguro algo mejor relativamente sino que en la intuición evidente misma le agrego un nuevo valor"26. La mera corrección (Richtigkeit) del juicio no le atribuye valor al juicio mismo cuando no es realizado sobre el fundamento de una motivación racional. Cuando el sujeto se decide racionalmente (evidencialmente) por lo mejor en su campo práctico, agrega al querer objetivamente correcto un valor superior. Husserl sostiene que "solo en estos casos, lo que confiere valor residiría originariamente en el juicio mismo, la corrección residiría originariamente en la evidencia intuitiva y determinaría originariamente lo tenido por valioso"27. En el juzgar evidencial, el sujeto que juzga vivencia (erlebt) el auténtico deber, vivencia la motivación racional; no enuncia simplemente "esto es así", sino que se orienta a los fundamentos y a las razones de lo juzgado. Tenemos, ahora, la conciencia evidente de la corrección del juicio y, precisamente, porque el juicio tiene en sí mismo el valor de la evidencia, reconocemos el valor de su objeto de manera evidente. El valor del juicio y el valor de lo mentado en el juicio refieren uno a otro en la medida en que el sujeto, en la vivencia de la racionalidad de la elección, constituye él mismo la corrección de la meta volitiva. Husserl habla, en este contexto, de "un cumplimiento mediante la meta (Ziel) misma, un cumplimiento interno de la adecuación de la mención en el darse de lo mentado"28. De este modo, el imperativo objetivo continúa siendo válido en su exigencia de hacer lo mejor entre lo alcanzable, pero lo que comienza a cobrar relevancia es el momento noético de la exigencia. Bajo estas consideraciones, el imperativo categórico no solo demanda hacer lo mejor entre lo alcanzable, sino que es complementado con la expresión noética "iQuiere evidencialmente lo mejor entre lo alcanzable!”29; “iQuiere y actúa racionalmente! Si tu querer es correcto, no es simplemente por eso valioso; solo el querer racional es valioso"30. Así, "solo cuando el sujeto del querer... él mismo en su querer se deja deter-

\footnotetext{
25 Ibid., p. 356.

26 Ibid., p. 145.

27 "Nur in solchen Fällen liege das Wertgebende originär im Urteilen selbst; die Richtigkeit liege originär gegeben in der Einsichtigkeit und bestimme dann originär die Werthaltung" (Ibid., p. 152).

28 Cf. ibid., p. 153.

29 "Wolle einsichtig das Beste unter dem erreichbaren!" (Ibid., p. 357).

30 Ibid., p. 153.
} 
minar por motivaciones racionales, cuando no cede ciegamente en su voto volitivo, sino que constituye originariamente en su querer la corrección de la meta (Zielrichtigkeit), es en sí mismo consciente de un deber que corresponde adecuadamente al querer; solo entonces tiene valor originario"31.

De lo expuesto hasta este punto podemos concluir que una persona puede actuar en conformidad con el imperativo categórico cuando se halla enfrentada a un campo práctico considerado de modo objetivamente cerrado, reconoce las relaciones entre valores y entre valores y bienes, y elige la opción que permita realizar la mayor cantidad de valores positivos. La corrección de la voluntad se halla pre-delineada en la corrección de la valoración que subyace a ella, i.e., para que un acto volitivo sea considerado correcto, la valoración que está en su base debe ser correcta. Con todo, como hemos visto, no se trata simplemente de evaluar y querer casualmente de manera correcta, pues, para que una voluntad no sea meramente correcta, sino una voluntad racional, debe reconocer con evidencia el valor de la racionalidad de una meta. Con el fin de ofrecer un panorama del camino que recorren las reflexiones de Husserl sobre la base de lo expuesto hasta aquí, antes de pasar a su crítica al imperativo categórico kantiano, pondremos de relieve un aspecto que comenzará a aparecer en el centro de la discusión en los textos de la década de 1920: que la acción según el imperativo categórico supone no solo que el sujeto considere la racionalidad de cada acto de elección, sino que se considere a él mismo -en cuanto sujeto ético- como un ser racional y ponga como telos de su vida la idea de una autoconfiguración total en el sentido de la razón. En otras palabras, se trata del paso desde la pregunta "¿cómo elegir lo mejor en una situación determinada?" hacia la pregunta “¿cómo "llegar a ser" cada vez mejor?”, “¿cómo configurar la totalidad de mi vida como una vida conforme a la razón, de modo que sea "la mejor vida posible"?"

\section{El imperativo categórico y la mejor vida posible}

Como adelantamos en la Introducción, la reelaboración de la concepción husserliana del deber práctico, que tiene lugar en los cursos y textos elaborados en su periodo en la Universidad de Friburgo, debe ser comprendida a la luz de las críticas realizadas por Husserl en esta época a su primera apropiación del imperativo categórico, tal como la hemos expuesto en los apartados anteriores. Uno de los ejes fundamentales de la crítica a su posición anterior es la perca-

${ }^{31}$ Ibid. 
tación de que la determinación formal de la razón práctica es solo un aspecto de la ética y, sobre todo, que la idea de un sujeto que somete sus actos a una "ley de absorción" que exige la realización del valor objetivamente más alto es demasiado anónima. Expresado de otro modo, Husserl advierte la necesidad de un abordaje más concreto que tome en consideración la individualidad de la persona en la determinación de una obligación moral. Las observaciones críticas respecto de los desarrollos anteriores llegan a un punto tal que, en un pasaje del curso Introducción a la Filosofía de 1919/20 -uno de los textos en los que Husserl expresa con mayor claridad sus críticas a su concepción temprana-, ha sostenido que "una ética guiada según el mero imperativo categórico, tal como lo ha sido aquí, en conexión con Brentano, no es ninguna ética" 32 . Sin embargo, los motivos de tan taxativa afirmación no pueden encontrarse exclusivamente en problemas internos a la teoria, tal como ha sido formulada en los cursos tempranos. Un abordaje de los cambios que tuvieron lugar en su pensamiento exclusivamente realizado por la vía negativa no es suficiente para dar cuenta de los aspectos centrales de su nuevo enfoque. La nueva concepción sobrepasa el intento de solucionar problemas del enfoque anterior y cobra el sentido de una reinterpretación del deber práctico y de la racionalidad práctica que hace justicia al deber ético en su dimensión personal, esto es, al deber en la medida en que es mi deber. Para comprender esto debemos tener en cuenta que los cambios en la concepción husserliana de la ética corren paralelos a la consolidación del enfoque genético fenomenológico. Con esto nos referimos a que es la indagación genética lo que permite a Husserl realizar el paso desde el estudio de los actos de un yo vacío y formal, tal como había sido pensado en Ideas I, al estudio del sujeto de los actos en su densidad ontológica como persona. La determinación ontológica del yo posibilitada por la apertura a la dimensión histórica de la experiencia pone al descubierto que él no es tan solo "interioridad polar", sino que tiene un centro profundo, configurado por las habitualidades, convicciones y disposiciones adquiridas. En este marco, la idea de "persona ética" es la de un sujeto que tiene la capacidad de reconfigurar ese centro o núcleo personal en función de una meta. Esta consideración de la persona ética corresponde a una concepción de la vida humana como un proceso gradual de "despertar" que transcurre en la forma de la aspiración (streben), del empeño por realizar valores positivos y dar a la vida la forma de la evidencia y la legitimidad racional. Así, por ejemplo, en los escritos sobre Renovación, Husserl intenta dar cuenta de la progresiva configuración ética de la vida sobre la base de sus motivaciones

${ }^{32}$ Hua IX, p. 146. 
internas, esto es, como un proceso que, partiendo de la vida natural-animal y pasando por formas pre-éticas de auto-regulación de la vida humana que se desarrollan aún en una cierta ingenuidad, culmina en la forma superior de la vida auténticamente ética. Su intención es "desarrollar genéticamente la forma de la vida ética como una forma a priori esencial de toda vida humana posible, es decir, desarrollarla a partir de las motivaciones que pertenecen a ella esencialmente" ${ }^{33}$. En lo que concierne a nuestro tema, la indagación de la constitución de la personalidad ética en cuanto proceso de devenir-que se despliega en niveles de sucesiva perfección-y la correspondiente concepción de la vida como constante aspiración o empeño, ponen de manifiesto que lo que se juzga desde el punto de vista ético no son simplemente actos particulares, sino a la persona como una unidad y a sus actos como realizaciones progresivas de una meta superior proyectada para toda la vida. Bajo esta consideración, Husserl comienza a pensar la decisión ética como una decisión vinculante de por vida producto de una auto-meditación universal que cada hombre debe llevar a cabo una vez en la vida. En esta meditación, en sus palabras, "cada uno dice: quiero vivir mi vida, toda mi vida a partir de ahora y en todos sus actos y con todo su contenido de vivencias de modo tal que sea mi mejor vida posible (mein bestmögliches Leben), mi mejor posible, esto es, lo mejor que yo puedo. Esto es para mí la vida debida, la vida absolutamente debida" ${ }^{34}$.

Actuar moralmente implica, entonces, decidirse por el valor superior en una situación determinada, pero, sobre todo, significa comprometerse con él de modo que atraviese la totalidad de la vida práctica. Husserl subraya la diferencia entre las acciones morales consideradas de manera independiente y la personalidad moral en relación con la regulación universal de la vida al afirmar que "el querer y actuar puede ser puramente moral pero la personalidad moral es la idea de un sujeto que es moral en la universalidad de su vida, en todos sus actos" ${ }^{35}$. De ahí que el ideal ético apunte, en un nivel ulterior, a que el despertar de la "conciencia ética" (ethisches Gewissen) se convierta en una habitualidad o estilo de vida o (lo que es lo mismo) al desarrollo de una "disposición ética" (ethische Gesinnung), en el sentido de una inclinación a determinarse o decidirse de un modo particular. Luego, lo debido (Gesolltes) no es solo hacer lo mejor posible en cada ocasión particular, sino llegar a ser cada vez mejor. Ser una persona ética es "estar en el camino" hacia ello, "llegar

${ }^{33}$ Hua XXVII, p. 29.

${ }^{34}$ Hua XXXVII, p. 252.

${ }^{35}$ Ibid., p. 246. 
a ser" una persona ética. "Solo puedo hacerme bueno, no ser bueno, pero solo puedo hacerme bueno en el querer-hacerme-bueno"36.

La consideración del desarrollo de la persona ética en cuanto proceso pone de relieve una gradualidad en la perfección de la condición humana que se halla en la base de la construcción del ideal del "hombre ético". De modo que, junto a un ideal de perfección absoluta que -de acuerdo con Husserl-corresponde, en última instancia, a la idea de Dios, hay un ideal del ser humano perfectamente humano, que hace lo mejor posible en el sentido de que la mejor vida posible vive según su mejor conciencia ética. Lo central es que el ideal relativo de hacer lo mejor posible apunta al mismo tiempo hacia el ideal absoluto. De este modo, la vida ética individual del sujeto que hace lo mejor posible en toda circunstancia es, como dirá en otro texto, "absoluta en su relatividad" 37.

En virtud de esto, en las lecciones Introducción a la ética de 1920/24, Husserl expresa la exigencia práctica con la fórmula “¡Haz lo mejor según tu mejor ciencia y conciencia!"38. La interpretación del imperativo categórico a la luz de la expresión "la mejor ciencia y conciencia" expresa los niveles de sucesiva perfección que supone el desarrollo de la conciencia ética a los que nos hemos referido. Una formulación ulterior expresa la exigencia con las palabras: “¡Haz a partir de ahora y sin vacilar siempre lo mejor, cáptalo en cognición normativa y quiérelo en volición normativamente consciente!"39. Es decir, la idea del hombre ético es la de un sujeto que pone como meta la acción conforme a la razón no solo para cada acto, sino para toda su vida.

Como señalamos al comienzo, de esta concepción de la exigencia categórica se sigue que lo debido no es debido en virtud de consideraciones objetivas, sino en virtud de consideraciones que son inseparables de mi horizonte vital personal. De acuerdo con Husserl, cada persona tiene un ideal individual de sí mismo, un "verdadero yo" (wahres Ich), y lo que cada uno pone como meta de su vida es la realización progresiva de ese ideal. Así, la determinación del carácter ético de una persona implica juzgar si se ha mantenido o no fiel a ese ideal de sí mismo, si en cada acción se reconoce a sí mismo como su mejor yo ${ }^{40}$, como el hombre que quiere llegar a ser. Husserl expresa la proyección de un

\footnotetext{
36 "Ich kann nur gut werden und nicht gut sein, aber ich kann nur gut werden im Gut-werden-Wollen" (Hua XLII, p. 214).

37 Ibid., p. 437.

38 “Tue dein Bestes nach bestem Wissen und Gewissen!" Cf. Hua XXXVII, p. 7.

39 Ibid., p. 253.

40 La idea de lo "mejor posible" y del "mejor yo" se determina en cada caso sobre la base de las capacidades individuales de la persona y de sus variaciones.
} 
ideal individual en los siguientes términos: "El hombre en cuanto hombre tiene ideales. Su propio ser es formarse un ideal de sí mismo como este concreto yo personal, y un ideal de su vida entera -un doble ideal incluso, absoluto y relativo-, y tener que poner su empeño en la máxima realización posible del ideal; así ha de hacer el hombre si es que ha de poder reconocerse a sí mismo, según su propia razón, como ser humano racional, como verdadero y auténtico ser humano. Este ideal que late a priori en él, lo toma el hombre, pues, en su figura más originaria, de sí mismo, como su yo verdadero, como su mejor yo. Con que una sola vez haya el yo barruntado e intuido ese ideal, tiene ya que reconocer con evidencia que la forma de vida concorde con tal ideal, la forma ética de vida, no es sólo la mejor posible en términos relativos, -como si junto a ella pudieses aún seguir llamándose buenas otras distintas-, sino que es la única buena sin más, la que está 'categóricamente' exigida" ${ }^{41}$. De este modo, podemos concluir que, a la luz de los textos posteriores a las lecciones de Gotinga, el imperativo categórico ya no es solo relativo a las condiciones señaladas anteriormente, a saber: (1) el carácter contingente del campo práctico -dependiente del sujeto volitivo y del punto temporal-y (2) el reconocimiento de las relaciones entre valores y las relaciones entre valores y bienes, sino también a una tercera condición que podemos agregar ahora: (3) la convicción práctica de que la realización de estos valores es indispensable para toda vida humana, i.e., el reconocimiento del valor superior de la vida conforme a la razón. Luego, siguiendo la sugerencia de S. Rinofner-Kreidl, la determinación completa del deber práctico expresada por el imperativo podria ser formulada del siguiente modo: dado que en una situación cuento con un rango determinado de opciones, dado que reconozco que la decisión ética exige la realización de la acción que efectúe la mayor cantidad de valores positivos y evite la realización de valores que obstaculicen la realización de un valor superior, y dado que me considero un ser humano racional -que reconozco el valor superior de una vida conforme a la razón-, debo realizar en toda situación lo mejor entre lo alcanzable ${ }^{42}$.

Un último punto que debemos considerar es que, ya desde las lecciones tempranas, Husserl sostiene que las reflexiones sobre el imperativo categórico, que se originan en el marco de la práctica y la axiología formales, apuntan más

\footnotetext{
${ }^{41}$ Husserl, E., Renovación del Hombre y la Cultura. Cinco Ensayos, Serrano de Haro, A. (trad.), Barcelona: Anthropos Editorial, 2002, p. 37.

${ }_{42}$ Rinofner-Kreidl, S., "Husserl's Categorical Imperative and his Related Critique of Kant", en: Luft, S. y P. Vandevelde (eds.), Epistemology, Archeology, Ethics. Current Investigations of Husserl's Corpus, Londres/Nueva York: Continuum, 2010, pp. 188-210, p. 199.
} 
allá de ella al requerir la complementación sistemática de un a priori material de la vida afectiva, en el sentido de una lógica del sentimiento (Gefühlslogik) análoga a la lógica del juicio (Urteilslogik). En este punto el camino de la ética husserliana se separa de la tradición kantiana que considera que la elaboración de una ética a priori exige dejar fuera de consideración la particularidad del contenido de los objetos del valor y la voluntad. Por este motivo, una de las mejores formas de comprender en su especificidad la apropiación fenomenológica del imperativo es analizar las críticas dirigidas por Husserl al imperativo categórico kantiano. Este será el tema de la siguiente sección.

\section{La critica al imperativo categórico kantiano ${ }^{43}$}

Antes de abordar las críticas dirigidas específicamente a la formulación kantiana del imperativo categórico, atendamos brevemente a algunos de los rasgos generales de la concepción husserliana de la ética kantiana. En una reflexión sobre la relación de Husserl con la filosofia práctica kantiana, Roberto Walton ha resumido con claridad el punto focal que explica la compleja relación entre ambos filósofos al sostener que fue la búsqueda de un auténtico motivo moral la cuestión que vincula a Husserl con la ética kantiana y a la vez lo distancia de ella ${ }^{44}$. Husserl concede a Kant el mérito de haber luchado por una "moral de la obligación" (Pflichtmoral), oponiéndose, así, al modo en que las morales del sentimiento han conducido a la ética a consecuencias escépticas. Sin embargo, lamenta que, en su búsqueda de un auténtico motivo moral, Kant haya compartido el mismo prejuicio de aquellos a quienes criticaba, a saber, la sensualización de la esfera de los sentimientos, la comprensión de la vida afectiva como un condicionante fáctico que obstaculiza la acción según

\footnotetext{
${ }^{43}$ Husserl dictó cursos sobre la ética kantiana en varias ocasiones. En nuestro análisis tomaremos como referencia dos cursos en los que expuso con gran detalle su posición acerca del tema: el curso Grundfragen der Ethik de 1902/03 y el curso Einleitung in die Ethik, dictado en 1920 y repetido en 1924. La sección dedicada a la ética kantiana correspondiente al primer curso ha sido publicada en Hua XXVIII (pp. 402-418) y el curso de 1920/24 se encuentra publicado en Hua XXXVII (pp. 200-243). En lo que concierne a la literatura secundaria publicada sobre el tema, el estudio más amplio sobre la relación general entre Husserl y Kant es Kern, I., Husserl und Kant, La Haya: Martinus Nijhoff, 1964. Sobre temas específicamente éticos hasta el momento el estudio más profundo es Cobet, T., Husserl, Kant und die Praktische Philosophie, Würzburg: Königshausen und Neumann, 2003. Otros textos que tratan el tema son: Peucker, H., "Husserl's Critique of Kant's Ethics", en: Journal of the History of Philosophy, v. XLV, 2 (2007), pp. 309-319; Rinofner-Kreidl, S., "Husserl's Categorical Imperative and his Related Critique of Kant", o.c.; Trincia, F. S., "The Ethical Imperative in Edmund Husserl”, o.c.

${ }^{44}$ Cf. Walton, R., "Ética de la razón pura y ética de la mejor vida posible", en: Anuario de filosofía juridica y social, 24 (2004), p. 63.
} 
normas de la razón. Para comprender la posición de Husserl sobre la ética kantiana debe considerarse que él concibe la historia de la ética como la lucha entre dos perspectivas: la moral sentimentalista (Gefühlsmoral) y la moral intelectualista (Verstandesmoral), posiciones que expresan, a su vez, la oposición tradicional entre empirismo y racionalismo. En este contexto, la ética fenomenológica asume la tarea de superar la oposición que ha dominado la discusión ética, integrando las ventajas y desechando las desventajas de cada una de estas corrientes ${ }^{45}$. Así, Husserl comparte con el racionalismo la convicción de que hay, en la ética, una validez objetiva, pero rechaza la suposición de que esta validez se funde exclusivamente en una facultad intelectual. Con esto en mente, Husserl considera que la lucha contra el relativismo ha conducido al racionalismo kantiano a la presunción de que la motivación de la voluntad debe radicar en principios supra-empíricos y que una ley práctica de validez objetiva exige indefectiblemente la exclusión de todo componente proveniente del sentimiento. En términos generales, podemos decir que, según el análisis de Husserl, la ética kantiana, al naturalizar la esfera de la razón, ha pasado por alto las diferencias fenomenológicas y cualitativas entre sentimientos, las leyes de esencias que rigen la esfera afectiva y, sobre todo, la relación entre valoración y motivación volitiva. Bajo estas consideraciones, en el curso de Introducción a la ética, Husserl comienza su exposición crítica de la ética kantiana aludiendo a la distancia que separa sus análisis de los auténticos análisis fenomenológicos: "Nosotros, quienes, en cuanto fenomenólogos, hemos aprendido a no dejar pasar ningún concepto filosófico sin preguntar por su crédito, por su origen en fuentes de la conciencia originaria dadora de sentido, y a no dar por válida ninguna proposición a priori que no hayamos captado en la intuición pura como necesidad de esencias, no podemos sino tomar las deducciones kantianas con reservas. La deducción kantiana es una muestra de una argumentación trascendental realizada desde arriba. Se mantiene alejada de todos los análisis fenomenológicos" ${ }^{46}$.

La caracterización de la deducción kantiana como una argumentación realizada "desde arriba" debe comprenderse en relación con el modo en el que Husserl piensa a la ética fenomenológica como una ética que se ocupa, en

\footnotetext{
${ }^{45}$ La estrategia de reconducción a los errores cometidos por la tradición y el desvelamiento de la insuficiencia de las dicotomías que gobernaron la discusión ética a lo largo de la historia es también un motivo de inspiración brentaniana. En efecto, también Brentano con sus lecciones sobre ética pretendió mostrar un camino que une a las dos facultades humanas que el racionalismo y el empirismo habian separado. (Cf. GAE, p. 151; USE, p. 82).

46 Hua XXXVII, p. 212.
} 
primera instancia, de esclarecer la constitución originaria de los conceptos morales en el sentimiento. En este sentido, a diferencia de la ética kantiana, ella es una "ética desde abajo" 47 , es decir, una ética que reflexiona sobre los niveles más fundamentales de nuestra conciencia moral. En la medida en que la conciencia moral incluye la valoración, pues solo sobre su base es posible hablar de volición ${ }^{48}$, se impone al fenomenólogo necesariamente la tarea de estudiar el modo en el que el carácter valioso de los objetos es dado originariamente en actos afectivos. Vemos así que, si bien las motivaciones de la ética husserliana en sus orígenes -a saber, en lo concerniente a la fundamentación de una ética a priori y a la crítica al relativismo escéptico- son de indudable inspiración kantiana, uno de los rasgos más propios de la ética fenomenológica se define precisamente en oposición a ella. No obstante, el reconocimiento del rol de los sentimientos en la fundamentación de la ética no redunda en un retroceso a las posiciones empiristas criticadas, sino que depende de una reinterpretación de los conceptos en juego. Así, a la tesis kantiana según la cual "todos los principios prácticos, que presuponen un objeto (una materia) de la facultad de desear como fundamento de determinación, son en su totalidad empíricos y no pueden dar una ley práctica"49, Husserl opone una concepción de la ética que, sin renunciar al carácter a priori de la razón práctica, toma en consideración la vida afectiva poniendo de relieve la legalidad esencial que la recorre. Para la ética fenomenológica es fundamental reconocer que los sentimientos no son solo un tema de la organización psicofisica humana y que la relación entre el objeto y el sentimiento que motiva el acto volitivo no es gobernada de forma meramente empírica por leyes causales naturales, sino por leyes de esencias. En este sentido, sostiene que: "Kant no captó el verdadero sentido del a priori, a saber, a priori en el sentido de generalidad esencial pura, que es captada de modo indudable

\footnotetext{
47 "Ethik von unten" (Hua XXVIII, p. 414).

48 “¿Es pensable un querer libre de valoración, de sentimiento? ¿No sería un querer tal un contrasentido, como lo sería un tono sin intensidad, un color sin extensión o una representación sin algo representado? A priori, en universalidad esencial incondicionada, todo sujeto volitivo debe ser un sujeto valorante, sintiente." (Hua XXXVII, p. 214); "Querer, valorar, representar son una unidad entrelazada mediante fundamentación intencional: el representar da el objeto mentado, la valoración del objeto representado da el valor mentado, el querer mienta la realización de la objetividad valorada. Todo discurso sobre motivo en el sentido de fundamento volitivo, de fundamento de determinación de la voluntad tiene su origen en esta fundamentación del querer en un contenido de valor... Una motivación en la cual el yo como yo que quiere no fuera motivado por ningún contenido de valor, esto es, por ningún sentimiento, es simplemente impensable" (Ibid., pp. 214-215). 49 Kant, KpV, AA (05): 21. 14-16 (Cito según la edición académica: Kant, I., Gesammelte Schriften, Eds.: v. I-XXII Preussische Akademie der Wissenschaften, v. XXIII Deutsche Akademie der Wissenschaften zu Berlin, v. XXIV Akademie der Wissenschaften zu Göttingen: Berlin, 1900).
} 
como absoluta, como una validez independiente de toda facticidad casual. Lo que nos interesa especialmente es que él desconoce que, como en todo ámbito, así también en toda esfera de sensibilidad reinan tales leyes esenciales puras. No es de ningún modo cierto que la sensibilidad es sin más un título para la mera empiría y que excluye una necesidad incondicionada de la validez"50.

Si bien no es nuestra intención detenernos aquí en la caracterización de la noción husserliana del a priori y la posibilidad de un a priori material, bastará con señalar que, como se sigue de la cita, la fenomenología husserliana sostiene que la legalidad a priori no solo concierne a las relaciones entre conceptos sino también a cada región ontológica y, de este modo, también a las relaciones esenciales entre contenidos. Lo que Husserl intenta enfatizar es que, al definir el a priori en sentido negativo, esto es, como "independencia de la experiencia" ,i.e., de contenidos materiales, la noción de a priori material es, para Kant, contradictoria ${ }^{51}$.

Volviendo a las objeciones a la ética kantiana, hemos mencionado que Kant no reconoce las diferencias fenomenológicas entre sentimientos. Este señalamiento alude al hecho de que, para Kant, no es relevante qué tipo de sentimiento determina nuestra voluntad, pues "todos los principios prácticos materiales como tales son sin excepción de la misma clase y se hallan bajo el principio general del amor propio y de la propia felicidad"52. En términos generales, lo que es rechazado por Kant es la diferencia establecida tradicionalmente entre una facultad de desear inferior (que equivaldría al placer sensible) y una facultad de desear superior (que equivaldría al placer espiritual). Al no reconocer tal diferencia, Kant concluye que toda voluntad determinada por un sentimiento es guiada por un principio meramente empírico válido subjetivamente que, por este motivo, no puede servir como fundamento de la moralidad. La defensa husserliana de las diferencias cualitativas en la esfera sensible pone en primer plano que es absurdo subsumir todos los tipos de placeres -por ejemplo, el placer por la música, por el arte en general, por una teoría o el que podemos sentir por una comida- bajo el título de "afección patológica" 33 . Asimismo, en

\footnotetext{
${ }^{50}$ Hua XXXVII, p. 226.

${ }^{51}$ El ejemplo paradigmático del a priori material husserliano es la afirmación de que imposible un color que no tenga extensión. Se trata en este caso de un conocimiento que requiere de la experiencia pero que no por esto pierde carácter necesario.

${ }^{52}$ Kant, KpV, AA (05): 22. 6-8.

${ }^{53}$ En el mismo sentido, en Grundlegung und Aufbau der Ethik, Brentano se pregunta: "Wer wollte den Genuß beim Rauchen einer Zigarrete mit dem Genuß, der edlen Freude beim Anhören einer Beethovenschen Symphonie oder beim Anblick einer Raphaelischen Madonna vergleichen?!" (GAE, p. 186).
} 
este punto es importante señalar que el desconocimiento de los distintos tipos de sentimientos que afectan a la voluntad impide a Kant reconocer diferencias entre distintas formas de motivación volitiva. En contraste, uno de los rasgos más propios de la ética husserliana es la convicción de que el valor de la voluntad está determinado por el valor de su fundamento motivacional y que una voluntad buena lo es en virtud de que es motivada por un contenido positivamente valioso. En este contexto, una de las deficiencias más graves que Husserl detecta en la posición kantiana es el rechazo del fundamento motivacional de la voluntad. Desde un punto de vista fenomenológico, la noción kantiana de una voluntad que excluye toda determinación proveniente de los sentimientos, "es pura y simplemente impensable"54. En resumen, así como utiliza argumentos racionalistas para defenderse de las consecuencias relativistas del empirismo ético, Husserl critica a la ética kantiana con argumentos que ponen de relieve elementos propios de la tradición sentimentalista. A partir de aquí, su objetivo será mostrar el modo en que la ética fenomenológica logra combinar el reconocimiento de la importancia de la vida afectiva para la ética con la necesidad de determinar una obligación moral objetiva, evitando al mismo tiempo los peligros de ambas posiciones.

Sobre la base de esta presentación general, atendamos ahora sí, a las críticas dirigidas específicamente al imperativo categórico. Cabe aclarar que Husserl no concedió mayor relevancia a las diferentes formulaciones del imperativo kantiano. En sus críticas se refiere generalmente a la formulación básica Grundformel que prescribe: "Obra de modo tal que la máxima de tu voluntad pueda valer siempre al mismo tiempo como principio de una legislación universal" 55 . El siguiente texto del curso Preguntas fundamentales de ética de 1902/03 resume las deficiencias de las que, según Husserl, adolece el imperativo kantiano: "Toda acción realizada según una máxima que no es apta para convertirse en ley universal, es inmoral. Y esto significa que: es inmoral si el intento de generalizar la máxima en cuestión, considerada de modo puramente formal, resulta en una contradicción. ¡Pobres hombres! En este momento tengo hambre y estoy sentado a la mesa para comer. Hay ternera asada. ¿Me es permitido comer? Si lo hago, la máxima subyacente es la siguiente: una persona hambrienta sentada a la mesa en la que es servida ternera asada, comerá la ternera asada. ¿Podemos interpretarla como una ley general? Claramente no.

\footnotetext{
54 Hua XXXVII, p. 215.

55 "Handle so, daß die Maxime deines Willens jederzeit zugleich als Prinzip einer allgemeinen Gesetzgebung gelten könne" (Kant, KpV, AA (05): 30.38-39).
} 
¿Y qué sucedería con seres inteligentes que fueran por naturaleza herbivoros? Dañarian seriamente sus estómagos y colapsarian. Como la máxima señalada no puede ser interpretada como una ley general, consecuentemente, es inmoral comer ternera asada. En virtud de que esto es válido para todo alimento posible, deberíamos morir de hambre a fin de no contradecir la ley moral. // Sin embargo, podriamos intentar reformular la máxima, por ejemplo, toda persona hambrienta, comerá. Pero inmediatamente chocamos con una deficiencia inherente al carácter formal de la ley y del método que determina la posibilidad de generalización: evidentemente esta proposición puede ser aplicada en modo arbitrario. En todos los casos la máxima puede ser formulada de distintas maneras, incluyendo circunstancias de acción más generales o menos generales. De este modo, se da lugar a posibilidades diferentes y opuestas de generalización. Esto se muestra también en los ejemplos de Kant, por ejemplo, en el caso del préstamo de dinero. Si formulamos la máxima del siguiente modo: no es necesario que nadie mantenga sus promesas, podríamos concluir: de este modo, nadie haría una promesa nunca más, y la ley sería anulada. Pero ¿qué pasaría si formuláramos: no es necesario que nadie mantenga una promesa en los casos en los que no hay un reconocimiento escrito? En estos casos las personas serían más cuidadosas con sus documentos. //A propósito, es bastante extraño argüir que la ley práctica sería anulada si no quedaran casos de aplicación posibles. ¿Es anulada una ley penal si resulta como consecuencia de su implementación que los ciudadanos no roban o matan más?, ¿no prueba, por el contrario, su eficacia cuando tiene este efecto?, ¿y no es éste el propósito al que sirve su implementación?"56.

En primer lugar, hay claramente una crítica dirigida a la concepción kantiana de las máximas de la acción, más específicamente, un cuestionamiento de su relevancia. Esta crítica a la irrelevancia de las máximas tiene como objetivo poner en tela de juicio la relevancia del imperativo categórico mismo. Por otro lado, Husserl se suma a una larga tradición que critica el carácter formal del imperativo kantiano. Así, consideradas desde un punto de vista histórico, las críticas a la trivialidad de las máximas, la inmoralidad y el formalismo del imperativo kantiano no presentan una gran novedad. Más aun, debemos reconocer, en favor de Kant, que hay ciertos aspectos de la crítica de Husserl que se basan en una comprensión no totalmente adecuada de los conceptos kantianos. En este sentido, hemos visto que Husserl se refiere al caso de un

${ }^{56}$ Hua XXVIII, p. 415. 
sujeto que se halla en la situación de universalizar una máxima que no puede ser interpretada como ley general. Sin embargo, el ejemplo tomado para criticar la noción de máxima (la proposición "una persona hambrienta sentada a la mesa en la que es servida ternera asada, comerá ternera asada"), desde el punto de vista kantiano, no es más que una determinación subjetiva de la voluntad referida a un caso concreto y, en sentido estricto, no constituye una máxima sino una intención moralmente irrelevante. Una máxima o regla de acción es una instrucción reconocida voluntariamente concerniente a la dirección de la decisión. En rigor, para Kant, lo que se determina a través de la ley moral no es nunca una acción singular. Luego, a esta objeción, Kant podría responder que no debemos confundir las máximas de acción o reglas con cualquier tipo de decisión sobre cómo actuar en un caso concreto aquí y ahora ${ }^{57}$. La determinación "debo consumir ternera asada" no puede aspirar de manera razonable a convertirse en regla universal porque, como Husserl mismo señala, hay seres para quienes la ingesta de carne es perjudicial. En resumen, no es correcto afirmar que toda intención constituye una máxima. La ética kantiana no solo admite la existencia de intenciones que son moralmente irrelevantes (como comer ternera asada cuando tengo hambre) sino también de máximas que son moralmente indiferentes, es decir, que si bien no dan lugar a contradicciones pueden ser realizadas prácticamente sin necesidad de universalización. Si bien estos señalamientos no agotan las posibles respuestas que pueden ofrecerse desde la ética kantiana, bastan para mostrar que un análisis detallado podría resolver algunos de los problemas señalados por Husser158. Por lo demás, no

\footnotetext{
${ }^{57}$ R. J. Sullivan se refiere al uso inadecuado del imperativo kantiano del siguiente modo: “... many readers have been led to think that we should use the Categorical Imperative in all our everyday decisions. They have been misled into thinking that Kant claimed that our immediate moral decisions must look something like this: (1) Major premise: The Categorical Imperative; (2) Minor premise: The maxim of a possible action, for example, I want to try to become a philosophy teacher; (3) Conclusion: Therefore, I should not try to become a philosophy teacher (or anything else, nor should anyone else!). The implied reasoning process is this: if we were to apply the Categorical Imperative directly to this case and ask whether the maxim in question could also be a universal law for everyone, we should have to conclude that no one should try to teach philosophy, for then there would be no one to tend to all the other things that need doing, there would not be enough teaching jobs available, and so on. It is clear that using the Categorical Imperative in this fashion ends in an absurdity... What has gone wrong is a confusion between the kind of deliberation appropriate only to testing very general maxims for their moral acceptability and the kind of deliberation appropriate to our immediate decisions about how to act" (Cf. Sullivan, R.J., An Introduction to Kant's Ethics, Cambridge: Cambridge University Press, 1994, p. 42).

58 En este sentido, en el caso de la objeción concerniente a la aplicación de una ley penal podría señalarse también la diferencia establecida por Kant entre leyes judiciales y leyes morales. $C f$. Rinofner-Kreidl, S., "Husserl's Categorical Imperative and his Related Critique of Kant", o.c., p. 195ss.
} 
es mi interés aquí defender a Kant de las acusaciones de Husserl, sino mostrar cómo las críticas de Husserl a Kant contribuyen a precisar su propia posición. En este sentido, el imperativo husserliano se distancia de la formulación kantiana y de los peligros que, de acuerdo con él, ella acarrearía al no referirse a máximas sino a la realización de valores en acciones singulares. De este modo, una voluntad que no actúa en conformidad con el imperativo es una voluntad que, o bien falla en captar o aprehender las leyes axiológico-prácticas correspondientes, o bien carece de la motivación necesaria para hacerlo. Si alguien comete un error en su conducta ética, esto no sucede porque ha actuado según un principio no universalizable y tampoco porque ha sido influenciado por la sensibilidad, como sostendría Kant, sino porque no ha elegido bien ${ }^{59}$.

Por otro lado, Husserl relaciona la posibilidad de formular máximas arbitrariamente en una situación dada con su crítica al carácter formal del imperativo, que, como ya hemos señalado, constituye la objeción más difundida a la ética kantiana desde Hegel. En sintonía con esta tradición crítica, Husserl señala que la sola posibilidad de universalizar una máxima no puede garantizar su corrección ética e incluso puede justificar acciones inmorales. Se subraya, en este contexto, que el paralelo con la lógica muestra que, así como las leyes lógicas formales no son suficientes para determinar la corrección de las proposiciones materiales y establecer qué es verdadero, tampoco las leyes éticas formales pueden alcanzan para definir lo que puede ser considerado bueno ${ }^{60}$. De este modo, si bien la crítica de Husserl al formalismo kantiano puede llamar la atención para quien considere que, tomando solo su determinación formal, el imperativo husserliano tendria el mismo defecto, lo cierto es que la formalidad del imperativo tiene un sentido distinto para Husserl, ya que no excluye ni la motivacion, ni el contenido ni el objetivo de la acción ética. Así, la convicción husserliana de que, para decidir si en una circunstancia dada algo es éticamente exigido, es preciso evaluar el objeto de la voluntad y no solo su adecuación a reglas formales, salva a su imperativo de caer en un formalismo obsoleto. "La capacidad de universalización tomada de modo puramente formal es algo completamente vacío. Tenemos que saber por otro medio lo que es relevante y lo que no, qué motivos son correctos y cuáles no, para fundar las máximas como correctas y para poder reconducirlas a la ley universal que las justifica. El mero saber que si la máxima es correcta, es conforme con la ley -por tanto que ha de ser reducida a una pura ley-no puede nunca proveernos la ley misma; y sería

${ }^{59} C f$. Trincia, F. S., "The Ethical Imperative in Edmund Husserl”, o.c., p. 183.

${ }^{60}$ Cf. Hua XXVIII, p. 137-142.

ARETÉ Revista de Filosofia, vol. XXIX, N 1, 2017 / ISSN 1016-913X 
totalmente erróneo construir una formula por medio de una universalización cualquiera para luego observar si implica o no alguna contradicción"61.

\section{Consideraciones finales}

Dedicamos las consideraciones finales a una reflexión sobre el desarrollo de la concepción husserliana del imperativo categórico. Hemos visto que la doctrina del imperativo tiene su origen en el marco de su exposición de las leyes de la práctica formal. Más específicamente, es la llamada "ley de absorción", según la cual "en toda elección, lo mejor (das Bessere) absorbe lo bueno (das Gute) y lo óptimo (das Beste) de toda otra cosa que se ha de apreciar prácticamente en y para sí como buena en sí misma"62_,lo que conduce a Husserl a la formulación de una ley superior de la práctica que permite determinar qué opción, en un rango limitado de opciones posibles, posee valor práctico absoluto. En términos generales, el objetivo central de la ética temprana de Husserl fue elaborar una ética científica que defienda la validez de los valores y de los principios éticos. Por este motivo, los escritos tempranos presentan una concepción de la ética como una disciplina objetiva cuyo rigor y universalidad son solo comparables a los de la lógica. La defensa de la ética como una disciplina pura y de la validez a priori de sus normas debe considerarse en el marco del peligro que suponen, para él, las diversas formas de empirismo ético, especialmente del relativismo escéptico en el que derivan las posiciones psicologistas y biologistas. Sin embargo, esto no significa que Husserl niegue la dimensión empírica de la ética ni que pase por alto las diferencias entre las culturas y los momentos históricos o el innegable hecho de que nuestras valoraciones y voliciones se hallan indefectiblemente bajo la influencia y el condicionamiento de nuestra constitución psico-física y nuestra relación con el mundo circundante. Lo que la argumentacion allí presentada pretende mostrar es que, como sostiene John Drummond, "la influencia de estos factores empíricos en nuestra vida ética no es suficiente para justificar la afirmación de que la ética es una ciencia empírica, en la medida de que estos factores solo afectan el modo en que los principios

\footnotetext{
61 Ibid., p. 417-418.

62 "In jeder Wahl absorbiert das Bessere das Gute und das Beste alles andere an und für sich als praktisch gut Zu-Schätzende" (Hua XXVIII, p. 136). En un texto correspondiente a un periodo posterior encontramos la siguiente formulación de la ley de absorción: "Donde múltiples valores pueden ser realizados por un mismo individuo en un mismo instante de tiempo, siendo, en cambio, imposible su realización colectiva (por pares o en conjunto), la bondad del más alto de estos valores absorbe la bondad de todos los valores inferiores" (Hua XXVII, pp. 31-33).
} 
éticos son particularizados en diferentes circunstancias y las prácticas éticas en las que son realizados"63.

Aunque Husserl no niegue la relevancia de la dimensión aplicada de la ética, el recorrido realizado nos permitió constatar que para la determinación del deber práctico, en el contexto de sus lecciones tempranas, no toma aún en consideración la relación de cada sujeto con sus metas personales y el modo en que sus experiencias están a disposición e influyen en cada toma de decisión. Por el contrario, tal determinación está estrechamente unida allí a una actitud de imparcialidad o neutralidad que debe trascender estos determinantes en dirección hacia una mirada totalmente externa, la que es expresada en la apelación a la figura de un "espectador desinteresado". Como hemos visto, esto se debe fundamentalmente a que la fenomenología aún no cuenta con las herramientas metodológicas necesarias para dar cuenta del deber práctico en cuanto deber personal, ni de la constitución de la persona como proceso de devenir "hombre ético". Es la reelaboración del concepto de persona ética, posibilitada por la complementación del método estático mediante el enfoque genético fenomenológico, lo que permite reelaborar en dicha dirección su concepción de la ética y abordar la experiencia en la que somos interpelados por un deber que adquiere su sentido pleno en el marco de nuestra vida individual e intersubjetiva. Esta necesidad tampoco pasó inadvertida para Husserl en los escritos de Gotinga. Ya en dicho contexto, Husserl reconoció que con el abordaje formal "hemos conseguido la primera parte, ciertamente la más fundamental, en la fundación de una ética científica" ${ }^{64}$, pero falta mucho más para llegar a la "auténtica ética": "Qué sucede si nos representamos un sujeto racional en un contexto social, qué valores y no valores resultan de ello, en qué medida una unidad espiritual superior como la unidad de una familia, una asociación, un Estado, pueden constituirse por la socialidad y en qué medida esa unidad superior es ella idealmente valorable, comprensible como una especie de sujeto de rendimientos (als eine Art Subjekt faßbar für Leistungen) que pueden ser buenos o malos. Las lineas que parten de allí conducen a la auténtica ética, la ética individual y social" ${ }^{65}$. A la luz de esta convicción, sus reflexiones posteriores sobre el deber práctico toman cada vez en mayor consideración la aplicación del imperativo en el contexto de la vida ética personal y el entrelazamiento de la vida ética individual en la vida

${ }^{63}$ Drummond, J., "Moral Objectivity: Husserl's Sentiment of the Understanding", en: Husserl Studies, v. XII, 2 (1995), pp. 165-183, p. 167.

${ }^{64}$ Cf. Hua XXVIII, p. 141.

${ }^{65}$ Ibid., pp. 140-141. 
ética comunitaria. Si bien esto podría conducir a la conclusión de que hay, en la ética husserliana, un progresivo abandono del imperativo categórico, sin embargo, aunque es innegable que en sus últimos escritos las referencias a él no son tan predominantes como lo habian sido en las lecciones de Gotinga, no resulta tan evidente que los cambios en su concepción de la ética impliquen el abandono completo de la doctrina del imperativo y no más bien una progresiva concretización y ampliación, desde la primera formulación hasta convertirse en un imperativo de carácter comunitario ${ }^{66}$ en que lo mejor posible está representado por una comunidad del amor (Liebesgemeinschaft). En efecto, ya en un texto de 1911, Husserl afirma que la "expresión provisoria del imperativo" requiere cuidadosas y profundas reflexiones concernientes a la determinación de su "sentido, limites y presupuestos formales", y que esta tarea constituye un fragmento fundamental de toda ética pura y el primer fragmento de una investigación sistemática de la esencia de la razón práctica y, con mayor precisión, de la razón práctica formal"67. En lo que concierne a las modificaciones que experimenta el imperativo, cabe mencionar que, en Renovación, Husserl advertirá que el imperativo categórico "aún siendo tal imperativo, es una forma significativa pero vacía de contenido, de todos los imperativos individuales posiblemente válidos de determinado contenido... Cada hombre tiene, pues, además de su individualidad, su idea ética individual y su método ético individual, su imperativo categórico individual determinado en concreto para su caso"68. En esta dirección, el summum bonum, organizado en un sistema de valores, será luego expresado a través de la noción husserliana de "vocación" o "misión" (Berufung) que coincide, en su sentido más amplio, con el concepto de "deber absoluto" (absolutes Sollen). Es interesante llamar la atención en este punto sobre el progresivo reconocimiento de la relevancia ética de los determinantes personales que tiene lugar incluso al interior de los textos de la década de 1920. Con esto nos referimos a que, mientras que en los artículos sobre Renovación Husserl aún considera que la vida vocacional es una forma de vida pre-ética -en virtud de que carecería de una justificación según normas racionales-, en los textos en los que encuentra en el amor una fuente de normatividad ética legitima reconoce un estatus ético pleno a la vida vocacional e incluso postula como modelo de la vida ética la vocación fundada en el deber de la madre con su hijo. En este punto, Husserl debe enfrentarse a los problemas que conciernen a

\footnotetext{
66 Cf. Hua XXVII, p. 118.

${ }^{67}$ Hua XXVIII, p. 221.

${ }^{68}$ Hua XXVII, p. 41. Cf. también Hua XLII, p. 321.
} 
la relación entre amor y racionalidad (específicamente, al vínculo entre el amor como fenómeno instintivo y su especificidad en cuanto fenómeno ético) y a la posibilidad de fundar un vínculo ético comunitario de extensión universal en un fenómeno (el amor) que se caracteriza originariamente por su exclusividad. Se trata de temas de gran complejidad, abordados en textos que han sido publicados en gran parte en el tomo XLII de la serie Husserliana.

Antes de finalizar, es preciso referirnos a una última cuestión que es fundamental para comprender la especificidad de la ética fenomenológica respecto de otras. Hemos señalado insistentemente que la acción según el imperativo requiere una captación de valores como motivos del obrar y que esta captación motivante tiene lugar por medio de actos del sentimiento. Así, a la pregunta “¿qué hace de una voluntad una voluntad buena?" hemos respondido que un acto volitivo no puede ser calificado como bueno por motivos puramente cognitivos. Especialmente, a través de la crítica a la ética kantiana, ha quedado de manifiesto que, para Husserl, todo acto de la voluntad está basado en una aprehensión de valores mediante actos pertenecientes a la esfera de la afectividad y que llamamos "bueno" a lo que, en un acto de valoración, aprehendemos como positivamente valioso y, en virtud de las reglas de conveniencia práctica, tomamos como correlato de nuestra voluntad, asumiéndolo como meta a realizar. Ahora bien, una de las amenazas que acecha a toda teoria que reconoce el rol constitutivo de la afectividad para la ética es la posibilidad de que los conceptos éticos fundados en actos afectivos sean reducidos a acontecimientos psicológicos contingentes de los cuales no se puede predicar ningún tipo de normatividad. En sentido contrario, un problema igualmente grave surge si, al intentar evitar esta reducción, se culmina en una concepción teorética de los actos de la esfera afectiva. En la ética husserliana, esta última amenaza se ve agudizada por el hecho de que la razón lógica presenta una ventaja frente a la razón práctica. Ella no solo tiene la posibilidad de determinar validez y legitimidad en su propio ámbito, sino también en todos los ámbitos de juicios posibles, esto es, también en el ámbito de la razón valorativa y volitiva. La razón práctica es una razón "muda y, en cierto modo, ciega" ${ }^{69}$, que necesita actos de la razón lógico-teórica que lleven a la luz aquello que es mentado por ella. En este contexto, uno de los ejes centrales de la ética temprana de Husserl es la defensa de una concepción de los actos axiológico-prácticos que no los reduce a conocimientos de carácter teorético pero que, a la vez, pretende conservar

${ }^{69}$ Hua XXVIII, p. 68. 
para ellos una exigencia de evidencia y legitimación. Sobre esta concepción de los actos del valorar y el querer, se asienta su intento general de elaborar una ética que, sin renunciar a la exigencia de normatividad racional, reconozca a la vida afectiva como su fundamento.

\section{Bibliografia}

Brentano, F., Grundlegung und Aufbau der Ethik, 1ra. edición, Berna: Francke Verlag, 1952.

Brentano, F., Vom Ursprung sittlicher Erkenntnis, 2da edición, Leipzig: Meiner, 1922.

Cobet, T., Husserl, Kant und die praktische Philosophie, 1ra. edición, Wurzburgo: Königshausen und Neumann, 2003.

Drummond, J., "Moral objectivity: Husserl's Sentiment of the Understanding", en: Husserl Studies, v. XII, (1995), pp. 165-183. https://doi.org/10.1007/bf01417589

Husserl, E., Vorlesungen über Ethik und Wertlehre (1908-1914), Husserliana XXVIII, 1ra. edición, Dordrecht/ Boston/Londres: Kluwer Academic Publishers, 1988.

Husserl, E., Aufsätze und Vorträge (1922-1937), Husserliana XXVII, 1ra. edición, Dordrecht/Boston/Lancaster: Kluwer Academic Publishers, 1989. Traducción parcial al español: Renovación del Hombre y la Cultura. Cinco Ensayos, 1ra. edición, Serrano de Haro, A. (trad.), Barcelona: Anthropos Editorial, 2002.

Husserl, E., Einleitung in die Philosophie, Vorlesungen 1916-1920, Husserliana Materialien IX, 1ra. edición, Dordrecht: Springer, 2012. https://doi. org/10.1007/978-94-007-4659-6

Husserl, E., Einleitung in die Ethik. Vorlesungen Sommersemester 1920/1924, Husserliana XXXVII, 1ra. edición, Dordrecht/Boston/Londres: Kluwer Academic Publishers, 2004.

Husserl, E., Grenzprobleme der Phänomenologie, Texte aus dem Nachlaß 1908-1937, Husserliana XLII, 1ra. edición, Dordrecht/Heidelberg/Nueva York/Londres: Springer, 2013.

Kant, I., Gesammelte Schriften Eds.: v. I-XXII, Preussische Akademie der Wissenschaften; v. XXXIII, Deutsche Akademie der Wissenschaften zu Berlin; v. XXIV, Akademie der Wissenschaften zu Göttingen, Berlín, 1900.

Melle, U., "The Development of Husserl's Ethics", en: Études Phénoménologiques, v. XIII-XIV (1991), pp. 115-135.

Peucker, H., "Husserl's Critique of Kant's Ethics", en: Journal of the History of Philosophy, V. XLV, 2 (2007), pp. 309-319.

Rinofner-Kreidl, S., "Husserl's Categorical Imperative and his related critique of Kant", en: Luft, S y P. Vandevelde (eds.), Epistemology, Archeology, Ethics. Current Investigations of Husserl's Corpus, Londres/Nueva York: Continuum, 2010, pp. 188-210. https://doi.org/10.5040/9781472546425.ch-012

Sullivan, R.J., An Introduction to Kant's Ethics, 1ra. Edición, Cambridge: Cambridge University Press, 1994. 
Trincia, F., "The Ethical Imperative in Edmund Husserl”, en: Husserl Studies, v. XXIII, (2007), pp. 169-186. https://doi.org/10.1007/s10743-007-9022-2

Walton, R., "Ética de la razón pura y ética de la mejor vida posible“, en: Anuario de filosofia juridica y social, v. XXIV, 2004, pp. 63-81.

Recibido: 16/04/2016

Aceptado: 06/08/2016 